\title{
Good Medication Adherence and its Association with Meaning in Life among Thai Individuals with Schizophrenia
}

\author{
Teerapat Teetharatkul, M.D., Jarurin Pitanupong, M.D.
}

Department of Psychiatry, Faculty of Medicine, Prince of Songkla University, Hat Yai, Songkhla 90110, Thailand.

Received 10 November 2021 • Revised 23 December 2021 • Accepted 18 January 2022 • Published online 21 February 2022

\begin{abstract}
:
Objective: To study medication adherence, meaning in life, the association of medication adherence and meaning in life among Thai individuals with schizophrenia.

Material and Methods: This cross-sectional study surveyed all outpatient individuals with schizophrenia that followed up at the Psychiatric outpatient clinic, Songklanagarind Hospital. Three questionnaires were used:1) Demographic information 2) Medication adherence questionnaire and 3) The meaning in life questionnaire. Descriptive statistics were calculated using proportions, median and inter-quartile range (IQR) or mean and standard deviation (S.D.).
\end{abstract}

Results: According to the study period; from December 2020 to March 2021, there were 110 respondents. Most of the respondents (94.5\%) attended regular follow-ups, via doctor' appointments. The majority of them were male (56.4\%), single (76.4\%), and Buddhist (82.7\%). The mean age was $42.3 \pm 11.8$ years. According to the medication adherence questionnaire, all participants (100\%) had good medication adherence scores. Concerning meaning in life, most of the participants had high scores in all subparts of meaning in life; the presence of meaning in life and looking for something that made their lives feel purposeful and meaningful. There was no relationship between meaning in life scores and demographic characteristics ( $p$-value>0.050). As all participants $(100 \%)$ had good medication adherence scores, the association between medication adherence and meaning in life could not be established in this study.

Conclusion: Most individuals with schizophrenia had good medication adherence as well as meaning in life. The search for meaning in life and meaning in taking medications may decrease negative medication attitudes and change the meaning of the illness.

Keywords: adherence, meaning in life, medication, patient, schizophrenia

Contact: Assoc. Prof. Jarurin Pitanupong, M.D.

Department of Psychiatry, Faculty of Medicine, Prince of Songkla University, Hat Yai, Songkhla 90110, Thailand.

E-mail: pjarurin@medicine.psu.ac.th

(c) 2022 JHSMR. Hosting by Prince of Songkla University. All rights reserved.

This is an open access article under the CC BY-NC-ND license

(http://www.jhsmr.org/index.php/jhsmr/about/editorialPolicies\#openAccessPolicy).
J Health Sci Med Res 2022;40(5):533-541 doi: $10.31584 /$ jhsmr.2022864 www.jhsmr.org 


\section{Introduction}

Schizophrenia is a long-term, chronic mental illness. ${ }^{1}$ It is a disease that has residual symptoms and functional impairment. Therefore, both biological management and psychiatric rehabilitation for individuals with schizophrenia are essential to improve and recover the patient's quality of life and to lessen the burden for family members. ${ }^{2}$ The core concept of schizophrenia management is the combination of medication, ensuring patients gain insight, and the coaching of necessary community-living skills; such as, integrating patients back into society; via employment or an occupation can reduce or relieve stigma. Although, some individuals with schizophrenia gain insight well, the reality of this illness causes them to suffer from stigmatization, and because of this, patients usually deny or refuse medication; which in turn makes them relapse. ${ }^{3}$

Nowadays, antipsychotic medications play an effective role in schizophrenia symptom control; however, medication adherence for individuals with schizophrenia requires continuous long-term treatment to control symptoms, prevent relapse and avoid consequences. ${ }^{1}$ The major problem in the management of individuals with schizophrenia is non-adherence. ${ }^{4}$ The prevalence of nonadherence among schizophrenia was $28.8 \%$. Concerning medication non-adherence, patients are divided into two groups: intentional non-adherence; including those who deny medication, and unintentional non-adherence; including those with cognitive impairment. ${ }^{5}$ Intentional nonadherence is related to impaired insight, whilst unintentional non-adherence is derived from neurocognitive deficiency ${ }^{6,7}$ that affects the defective executive performance, or forgetting about their medication. ${ }^{8}$ Identified risk factors for nonadherence among individuals with schizophrenia included: impaired insight, stigmatization, cognitive deficiency, drug or alcohol abuse, medication attitudes or beliefs, negative subjective response to treatment ${ }^{5,9}$, and regarding the disorder as a minor or perceived mild utility from treatment. ${ }^{1,3}$
Due to having a chronic mental illness, some individuals with schizophrenia lose meaning in life. The presence of meaning in life is expected as: self-appraisal, personal growth, and altruistic with spiritual behaviors. It is positively related to intrinsic religiosity, agreeableness, extraversion, and well-being; whilst, it is negatively related to depression and anxiety. Whilst searching for meaning in life is hedonic behavior, which positively relates to rumination, religious quests; past-negative and present fatalistic time perspectives negatively affect both neuroticism and depression. In addition, it is negatively related to future time perspectives, close-mindedness (dogmatism), and well-being. ${ }^{10,11}$ Hence, over the course of this chronic mental illness, the presence of meaning in life is a significant issue for promoting a patient's good medication adherence, and well-being or graceful mental health.

In Thailand, the Department of Psychiatry, Faculty of Medicine, Prince of Songkla University, applies the: "narrative" and "homestay" models for psychiatric rehabilitation intervention. The narrative model is employed to search for meaning in life, and to modify the meaning of the illness for taking medication. In addition, the homestay model has been used for de-stigmatization. ${ }^{12}$ Individuals with schizophrenia then have treatment behavior changes, not only medication adherence, but also self-esteem or core concepts of self. ${ }^{13}$ These are due to individuals with schizophrenia having a new perspective of the illness, and accepting medication as necessary for life with this disease. In addition, the return to society or stigmatization is not a problem anymore. They may feel less shy and remake themselves as valuable people; for example: a volunteer that helps people in the community. In summary, the burden of family and oneself seems to decrease, while social function would be increased. ${ }^{14}$ Thus, this study purposed to study the medication adherence and meaning in life among individuals with schizophrenia. The relationships of good or poor medication adherence and meaning in life 
among individuals with schizophrenia were also identified. Additionally, the definition of good medication adherence in this study means that from the prescribed medication, the patient followed a prescribed schedule, neither took lower nor higher doses, did not completely abandon medication ${ }^{6}$, nor reject attending ordinary visits or being admitted into the hospital. ${ }^{15,16}$ Meaning in life was divided into 2 types: the presence of meaning in life and the search for meaning in life..$^{10,11,17}$

\section{Material and Methods}

The Ethics Committee of the Faculty of Medicine, Prince of Songkla University approved this cross-sectional study (REC. 63-202-3-1). Participants with schizophrenia, who visited the psychiatric outpatient clinic, were invited into this study by a psychiatric nurse. Informed consent from the participants was obtained before collaboration. They could agree or disagree to participate in the study, and could leave the study at any time.

A cross-sectional study surveyed all outpatient individuals with schizophrenia that followed up at the Psychiatric outpatient clinic, Songklanagarind Hospital; from December 2020 to March 2021. Inclusion criteria were individuals with schizophrenia who were diagnosed by psychiatrists for more than one year: based on the International Classification of Diseases $10^{\text {th }}$ code F20.0-F20.9, and were retrieved from the medical register, had been screened for mental capacity (judged by an outpatient psychiatric nurse), and were willing to complete all parts of the questionnaires. Exclusion criteria were individuals with schizophrenia who were unable or lacked the mental capacity to complete all the questionnaires, or felt it was inconvenient for them to collaborate and wanted to stop participating.

The participants were approached by a researcher and were invited to collaborate, by introducing the overview of the information and given the rationale contained in the research. In cases of those who cooperated, the researcher distributed self-reporting questionnaires; these were explained to the participants in detail. Additionally, participants were permitted to take a few minutes to deliberate whether or not to join the survey. To assure the participants' identities would be protected signatures of participants were not desired. Furthermore, we informed them that their data would remain anonymous, and highlighted that they could withdraw at any stage of the questionnaire without giving any reasons; additionally, this act would not affect their regular treatment. All participants were permitted to finish and return the questionnaires promptly or at a later time. They could either submit the questionnaires at the front of the clinic or return and leave them at the Psychiatry Department at a later time; therefore, protecting respondent confidentiality was retained.

We tried to calculate the sample size by the $G^{*} P o w e r$ program. We estimated Cohen's effect size at medium (0.3), because there has been no research on the association of the meaning in life and medication adherence in the past, and used Alpha=0.05, and Power=0.8. However, from the number of patients in the past, there were only 30 outpatient individuals with schizophrenia per month: all of these were collected for this study.

\section{Measures}

1. Personal and general demographic information comprised of gender, age, religion, income, working information, marriage status, hometown, caffeine or alcohol consumption, substance usage, and underlying diseases.

2. The Medication adherence scale in Thai (MAST) uses 8 items, rated on a 0-5 scale, with the total scores ranging from $0-40$. The cut-off point of MAST is 34. A score of less than 34 indicates that the participant had good medication adherence. The specificity and sensitivity were $89.7 \%$, and $85.8 \%$, respectively. The positive and negative predictive values were $90.6 \%$ and $84.7 \%$, respectively. The Cronbach's alpha coefficient of MAST was $0.828 .^{15,16}$ 
3. The meaning in life questionnaire (MLQ) uses 10 items, rated on a 5-point scale from: "absolutely true" to "absolutely untrue", with total scores ranging from 10 to 50. MLQ has 2 subscales: the presence of meaning in life and the search for meaning in life. The presence of meaning subscale measured how fully respondents feel their lives are of meaning; whereas, the search for meaning subscale measured how motivated and engaged respondents are in efforts to find meaning or deepen their understanding of meaning in their lives. ${ }^{17,18}$ The higher the score indicates that the participant had more meaning in life. The Cronbach's alpha coefficient of the presence of meaning subscale and search of meaning subscale were 0.73 and 0.78 , respectively. ${ }^{18}$

All analysis was performed using $\mathrm{R}$ version 3.2.1. A level of significance of 0.05 was used in this study. The Shapiro-Wilk test was used to test the normality distribution. Descriptive statistics were calculated using proportions, mean and standard deviation (S.D.), or median and interquartile range (IQR). The relationship between meaning in life scores and all variables were tested by using the Kruskal-Wallis test (for more than 2 groups of independent variables), and Rank-sum test (for 2 groups of independent variables) when the data were non-normal, and using Student's t-test (for 2 groups of independent variables) if the data were normal.

\section{Results}

According to the study period, December 2020 to March 2021, there were 112 individuals with schizophrenia who had set follow-up appointments at the Psychiatric outpatient clinic; only 2 individuals with schizophrenia did not attend follow up at their set appointment date. This was because they received their medicine via the postal system. Hence, there were 110 respondents (94.5\%) who attended regular follow-ups by doctor appointments and participated in this study. The majority of them were male (56.4\%), single $(76.4 \%)$, and Buddhist (82.7\%). (Table 1) The mean age was $42.3 \pm 11.8$ years, and the median income (IQR) was 11,000 (5,000-20,000) Baht per month. Of all participants, only $14(12.7 \%)$ and 22 (20.0\%) participants had a history of alcohol consumption and substance usage within one month. The most common substance that the participants used was cigarettes (17.3\%). Additionally, some participants (24.5\%) had a physical illness; such as, hypercholesterolemia $(30.0 \%)$, diabetes $(22.2 \%)$, or hypertension (18.5\%).

Using the medication adherence questionnaire, all respondents (100\%) had a MAST score of less than 34; meaning they had good medication adherence (Table 1).

Table 1 Demographic characteristics and medication adherence $(n=110)$

\begin{tabular}{ll}
\hline Demographic characteristics & Number (\%) \\
\hline Gender & \\
Male & $62(56.4)$ \\
Female & $48(43.6)$ \\
Religion & \\
$\quad$ Buddhism & $91(82.7)$ \\
Islam/Christianity & $19(17.3)$ \\
Marital status & \\
$\quad$ Single & $84(76.4)$ \\
$\quad$ Married & $20(18.2)$ \\
$\quad$ Divorced & $6(5.5)$ \\
Education & $10(9.1)$ \\
$\quad$ Primary school and below & $100(90.9)$ \\
$\quad$ Secondary school and above & \\
Home town & $65(59.1)$ \\
$\quad$ Songkhla province & $45(40.9)$ \\
$\quad$ Other & $19(17.2)$ \\
Occupation & $38(34.5)$ \\
$\quad$ Government employee officer/State & $30(45.5)$ \\
$\quad$ enterprise officer/Private company employee & \\
Merchant/Personal business/Employee/ & \\
Agriculture & \\
Student & \\
$\quad$ Unemployed & \\
\hline
\end{tabular}


Table 1 (continued)

\begin{tabular}{ll}
\hline Demographic characteristics & Number (\%) \\
\hline $\begin{array}{l}\text { History of alcohol consumption (within 1 month) } \\
\text { Yes }\end{array}$ & $14(12.7)$ \\
No & $96(87.3)$ \\
History of substance use (within 1 month) & \\
$\quad$ Yes & $22(20.0)$ \\
No & $88(80.0)$ \\
Physical illness & \\
No & $83(75.5)$ \\
Yes & $27(24.5)$ \\
Follow-up & $104(94.5)$ \\
Come on appointment & $5(4.5)$ \\
Before appointment & $1(0.9)$ \\
Come after appointment & \\
Medication Adherence scale & $110(100.0)$ \\
Good & $0(0.0)$ \\
Poor & \\
\hline
\end{tabular}

*Good medication adherence (score $<34$ ) and poor medication adherence (score $\geq 34)$
Table 2 Meaning in life

\begin{tabular}{|c|c|c|}
\hline Subscale & Median & IQR \\
\hline \multicolumn{3}{|l|}{ Presence of meaning in life } \\
\hline I understand my life's meaning. & 5.0 & $4.0-5.0$ \\
\hline My life has a clear sense of purpose. & 5.0 & $3.0-5.0$ \\
\hline $\begin{array}{l}\text { I have a good sense of what makes my } \\
\text { life meaningful. }\end{array}$ & 5.0 & $4.0-5.0$ \\
\hline $\begin{array}{l}\text { I have discovered a satisfying life } \\
\text { purpose. }\end{array}$ & 5.0 & $4.0-5.0$ \\
\hline $\begin{array}{l}\text { My life has no clear purpose. } \\
\text { Search for meaning in life }\end{array}$ & 1.0 & $1.0-4.0$ \\
\hline $\begin{array}{l}\text { I am looking for something that makes } \\
\text { my life feel meaningful. }\end{array}$ & 5.0 & $3.0-5.0$ \\
\hline $\begin{array}{l}\text { I am always looking to find my life's } \\
\text { purpose. }\end{array}$ & 5.0 & $4.0-5.0$ \\
\hline $\begin{array}{l}\text { I am always searching for something that } \\
\text { makes my life feel significant. }\end{array}$ & 4.5 & $3.0-5.0$ \\
\hline $\begin{array}{l}\text { I am seeking a purpose or mission for } \\
\text { my life. }\end{array}$ & 4.0 & $3.0-5.0$ \\
\hline I am searching for meaning in my life. & 5.0 & $3.0-5.0$ \\
\hline
\end{tabular}

IQR=interquartile range

Table 3 Meaning in life scores categorized by demographic characteristics

\begin{tabular}{|c|c|c|}
\hline Demographic characteristics & Median (IQR) & $\begin{array}{l}\text { Rank sum test } \\
p \text {-value }\end{array}$ \\
\hline Gender & & 0.023 \\
\hline Male & $40.5(36.0-46.0)$ & \\
\hline Female & $38.0(31.5-42.2)$ & \\
\hline Religion & & 0.333 \\
\hline Buddhism & $39.0(34.0-44.0)$ & \\
\hline Islam/Christianity & $42.0(34.0-46.0)$ & \\
\hline Marital status & & 0.578 \\
\hline Single/divorce & $38.5(34.0-44.0)$ & \\
\hline Married & $42.0(32.8-46.0)$ & \\
\hline Education & & $0.07^{\mathrm{a}}$ \\
\hline$\leq$ Secondary school & $40.0(34.5-46.0)$ & \\
\hline Diploma & $39.0(36.5-42.5)$ & \\
\hline Bachelor's degree and above & $38.0(30.0-42.0)$ & \\
\hline History of alcohol consumption & & 0.854 \\
\hline Yes & $40.5(34.0-45.5)$ & \\
\hline No & $39.0(34.0-44.0)$ & \\
\hline History of substance use & mean $\pm S . D$. & $0.106^{b}$ \\
\hline Yes & $40.7 \pm 5.5$ & \\
\hline No & $38.1 \pm 7.2$ & \\
\hline Physical illness & & 0.712 \\
\hline No & $38.0(34.0-44.5)$ & \\
\hline Yes & $40.0(35.0-44.0)$ & \\
\hline
\end{tabular}

${ }^{a} \mathrm{p}$-value from Kruskal-Wallis test, ${ }^{b} \mathrm{p}$-value from $\mathrm{t}$-test, IQR=interquartile range 
According to the meaning in life questionnaire, there were two subscales: the presence of meaning in life, and the search for meaning in life. Most of the respondents had a high score in all subparts of meaning in life. Moreover, all participants had the presence of meaning in life, and were looking for something that made their lives feel purposeful and meaningful (Table 2). There was no relationship between meaning in life scores and demographic characteristics ( $p$-value>0.050) (Table 3).

\section{Association between medical adherence and meaning in life}

As a result, the relationship between poor or good medication adherence and meaning in life could not be identified in this study.

\section{Discussion}

This study found that most participants (94.5\%) attended regular appointments to visit their doctor, and all of them (100\%) had good medication adherence. According to the meaning in life, all participants had the presence of meaning in life, and were searching for a meaning in life that gave their lives meaning and purpose. There was no relationship between meaning in life scores and demographic characteristics. Comparing medication adherence from our study with that reported by a previous study this was higher than the other study, which found $71.2 \%$ had adherence and $28.8 \%$ had non-adherence over 3 years. Additionally, a prior systematic review study found that $74.0 \%$ of patients had discontinued treatment within 18 months. ${ }^{19}$ These differences might be due to the use of differences in study instruments, study design, ethnicity, and background of the population. Regarding the previous data, factors positively associated with medication adherence were the perception of benefits in medication, and a good therapeutic relationship with the practitioners. ${ }^{1}$ Based on this study's results, most of the participants came to visit or follow up at set appointments, and took their medication regularly. Hence, other explanations of this study's results might point to the feature of the population as having a good therapeutic relationship with their practitioners, nurses, and the psychosocial intervention team or having good insight. Therefore, there was no gender differences in attitudes towards antipsychotic medications in our individuals with schizophrenia. Moreover, the prior study identified not only gender difference, but the different psychosocial and clinical factors that might account for the negative attitude towards antipsychotic treatment in male and female patients. ${ }^{20}$

Additionally, as the prior systematic review and meta-analysis concluded, successful interventions of medication adherence used a combination of educational and behavioral strategies. The combined use of educational sessions focusing on diagnosis, symptoms, medication, and relapse, with medication reminders at patients' homes and an intensive training program provided on a one-toone basis by skilled nurses that could improve medication adherence. Furthermore, such mixed interventions were deemed feasible to implement in daily practice. ${ }^{21}$

However, as the prior study found, the key drivers of worse medication adherence included: having poor or no insight, substance abuse, and medication beliefs. ${ }^{1}$ In addition, alcohol dependence, substance use, a negative medication attitude, and stigmatization are important impact factors of poor medication adherence. ${ }^{5,9}$ From this study, there were only $12.7 \%$ and $20.0 \%$ of participants who had a history of alcohol consumption and substance usage (cigarettes) within one month. Therefore, most of the population from this study had lower comorbidity disorders, than the prior study; making for more positive outcomes. However, many schizophrenia factors were found as having a directional relationship with worse adherence; such as, a lack of insight into their illness, meaning that they were not aware of the symptoms and consequences of their disease or illness. ${ }^{6,22,23}$ Therefore, future studies should search for an association between medication adherence and insight. 
In addition, except for the relationship with the physician having evidence suggesting a therapeutic relationship with monitoring and introduction to medication intake or being contributors to appropriate adherence, ${ }^{24}$ other external or environment-associated factors included: the stigma of the illness, living situations, and caretaker support as also being important. Other environmental factors that affect medication adherence positively also include family or social support ${ }^{25}$ and greater social activities. ${ }^{5}$ In contrast, the stigma of taking medication and having poor or no social support were found to negatively influence medication adherence. ${ }^{25}$ The prior study, from the Department of Psychiatry, Faculty of Medicine, Prince of Songkla University, identified that these individuals with schizophrenia had a moderate quality of life ${ }^{26}$, and most patients and caregivers perceived a low level of stigma. ${ }^{13}$ Moreover, most of the caregivers had no severe caregiver burden, with most burdens being at a mild level (22.0\%). The related, significant factors associated with family or caregiver burden were relapse of patient symptoms, unpleasant events in patient caring, and caregiver's physical illness. ${ }^{14}$ As mentioned previously, low burden and low stigma might have influenced this study outcome of medication adherence positivity.

Regarding the meaning in life, this study identified all participants had the presence of meaning in life, and the search for the meaning in life that made their lives feel meaningful and purposeful. That might be due to the influence of using the narrative model to help patients to change the meaning of the illness, and search for meaning in life; meaning in taking medications that decrease negative medication attitudes. Thus, all individuals with schizophrenia in our psychiatric department may have individual meaning for their lives. If someone feels their life is of meaning, it will either motivate or encourage that person to find deepen meaning, understanding, and acceptance for the entirety of their lives. ${ }^{17,18}$ Therefore, individuals with schizophrenia do not feel pain or suffering. In contrast, it enables them to recognize and accept it as part of life.

This survey was a cross-sectional study and used self-reporting for individual perception assessment. Beyond its high response rate, the information might not have led to bias. However, as medication adherence was measured only once, and used only one assessment tool; the results might have led to bias. Additionally, the population was limited to only individuals with schizophrenia who came to the hospital for regular appointments, and it did not cover individuals with schizophrenia who did not follow up according to appointments. Furthermore, the population was limited to only individuals with schizophrenia from the Psychiatric outpatient clinic, of Songklanagarind Hospital; therefore, it is too soon to generalize this information to a nationwide setting. Additionally, a small sample size could have influenced the results, perhaps future studies with larger sample sizes could be more representative.

Further surveys should investigate more individuals with schizophrenia within Thailand. Therefore, a multicenter survey is recommended. In addition, individuals with schizophrenia who are lost to follow-up, or have poor medication adherence should also be of concern. Moreover, further studies should employ a more quantitative method or contain a control group.

\section{Conclusion}

Most individuals with schizophrenia had good medication adherence as well as meaning in life. The search for meaning in life and meaning in taking medications may decrease negative medication attitudes, and change the meaning of the illness. Therefore, schizophrenia does not cause them pain or suffering, and it enables them to accept it as part of life. 


\section{Acknowledgement}

This project was fully funded by the Faculty of Medicine, Prince of Songkla University. The authors would like to acknowledge all the participants for their willingness to participate. We gratefully acknowledge Associate Professor Hutcha Sriplung as well as Ms. Kruewan Jongborwanwiwat and Mrs. Nisan Werachattawanand in regards to the statistical analysis. Moreover, we genuinely appreciate the Office of International Affairs, Faculty of Medicine, Prince of Songkla University for their assistance in editing the manuscript.

\section{Funding sources}

This research was funded by the Faculty of Medicine, Prince of Songkla University.

\section{Conflict of interest}

No conflicts of interests are declared.

\section{References}

1. Higashi K, Medic G, Littlewood KJ, Diez T, Granstrom O, De Hert M. Medication adherence in schizophrenia: factors influencing adherence and consequences of nonadherence, a systematic literature review. Ther Adv Psychopharmacol 2013; 3:200-18.

2. Fenton WS, Blyler CR, Heinssen RK. Determinants of medication compliance in schizophrenia: empirical and clinical findings. Schizophr Bull 1997;23:637-51.

3. Harrow M, Jobe TH. Factors involved in outcome and recovery in schizophrenia patients not on antipsychotic medications: a 15-year multifollow-up study. J Nerv Ment Dis 2007;195:406-14.

4. Acosta FJ, Hernandez JL, Pereira J, Herrera J, Rodriguez CJ. Medication adherence in schizophrenia. World J Psychiatry 2012;2:74-82.

5. Novick D, Haro JM, Suarez D, Perez V, Dittmann RW, Haddad PM. Predictors and clinical consequences of non-adherence with antipsychotic medication in the outpatient treatment of schizophrenia. Psychiatry Res 2010;176:109-13.

6. Acosta FJ, Bosch E, Sarmiento G, Juanes N, Caballero-Hidalgo A, Mayans T. Evaluation of noncompliance in schizophrenia patients using electronic monitoring (MEMS) and its relationship to sociodemographic, clinical and psychopathological variables. Schizophr Res 2009;107:213-7.

7. Hui CL, Chen EY, Kan CS, Yip KC, Law CW, Chiu CP. Detection of non-adherent behaviour in early psychosis. Aust $\mathrm{N} \mathrm{Z} \mathrm{J}$ Psychiatry 2006;40:446-51.

8. Robinson DG, Woerner MG, Alvir JM, Bilder RM, Hinrichsen GA, Lieberman JA. Predictors of medication discontinuation by patients with first-episode schizophrenia and schizoaffective disorder. Schizophr Res 2002;57:209-19.

9. Lieberman JA, Koreen AR, Chakos M, Sheitman B, Woerner M, Alvir JM, et al. Factors influencing treatment response and outcome of first-episode schizophrenia: implications for understanding the pathophysiology of schizophrenia. J Clin Psychiatry 1996;57:5-9.

10. Steger MF, Frazier $P$, Oishi $S$, Kaler M. The meaning in life questionnaire: assessing the presence of and search for meaning in life. J Couns Psychol 2006;53:80-93.

11. Steger MF, Frazier P. Meaning in life: one link in the chain from religion to well-being. J Couns Psychol 2005;52:574-82.

12. Taengbunngam $S$, Chincharoensup $D$, Vitayanont $A$. Attitudes towards mental illness of psychiatric patients, relatives of psychiatric patients and homeowners from a homestay family camp. J Psychiatr Assoc Thailand 2015;60:149-54.

13. Agrasuta $\mathrm{T}$, Pitanupong J. Perceived stigma in patients with schizophrenia and caregivers in Songklanagarind Hospital: cross-sectional study. Songkla Med J 2017;35:37-45.

14. Pitanupong J, Rueangwiriyanan C. Caregiver burdens in patients with schizophrenia and related factors. J Ment Health Thai 2019;27:95-106.

15. Kane JM. Compliance issues in outpatient treatment. J Clin Psychopharmacol 1985;5:22S-7S.

16. Perkins DO. Predictors of noncompliance in patients with schizophrenia. J Clin Psychiatry 2002;63:1121-8.

17. Steger MF, Shin JY. The relevance of the Meaning in Life Questionnaire to therapeutic practice: a look at the initial evidence. International Forum for Logotherapy 2010;33:95-104.

18. Chomchoed O. Caregiving experiences, sense of coherence, and meaning in life among family caregivers of patients with invasive cancers [Thesis]. Bangkok: Chulalongkorn University; 2009.

19. Lieberman JA, Stroup TS, McEvoy JP, Swartz MS, Rosenheck RA, Perkins DO, et al. Effectiveness of antipsychotic drugs in 
patients with chronic schizophrenia. N Engl J Med 2005;353: 1209-23.

20. Zhou J, Xiang YT, Li Q, Zhu X, Li W, Ungvari GS, Ng CH, et al. Gender differences in attitudes towards antipsychotic in patients with schizophrenia. Pstchiatry Res 2016;245:27681.

21. Loots E, Goossens E, Vanwesemael T, Morrens M, Van Rompaey B, Dilles T. Interventions to improve medication adherence in patients with schizophrenia or bipolar disorders: a systematic review and meta-analysis. Int J Environ Res Public Health 2021 18.

22. Olfson M, Marcus SC, Wilk J, West JC. Awareness of illness and nonadherence to antipsychotic medications among persons with schizophrenia. Psychiatr Serv 2006;57:205-11.
23. Velligan DI, Weiden PJ, Sajatovic M, Scott J, Carpenter D, Ross $R$, et al. The expert consensus guideline series: adherence problems in patients with serious and persistent mental illness. J Clin Psychiatry 2009;70:1-48.

24. Rettenbacher MA, Hofer A, Eder U, Hummer M, Kemmler G, Weiss EM, et al. Compliance in schizophrenia: psychopathology, side effects, and patients' attitudes toward the illness and medication. J Clin Psychiatry 2004;65:1211-8.

25. Hudson TJ, Owen RR, Thrush CR, Han X, Pyne JM, Thapa P, et al. A pilot study of barriers to medication adherence in schizophrenia. J Clin Psychiatry 2004;65:211-6.

26. Aunjitsakul W, Pitanupong J. Schizophrenias' quality of life and emotional intelligence in Songklanagarind Hospital. Songkla Med J 2018;36:61-71. 